\title{
Association of high-sensitive C-reactive protein with advanced stage $\beta$-cell dysfunction and insulin resistance in patients with type 2 diabetes mellitus
}

\author{
Andreas Pfützner ${ }^{1,2, *}$, Eberhard Standl ${ }^{3}$, \\ Hermann-Josef Strotmann ${ }^{4}$, Jan Schulze ${ }^{5}$, \\ Cloth Hohberg', Georg Lübben', Sabine \\ Pahler ${ }^{1}$, Thomas Schöndorf ${ }^{1}$ and Thomas \\ Forst ${ }^{1}$ \\ ${ }^{1}$ Institute for Clinical Research and Development, \\ IKFE, Mainz, Germany \\ ${ }^{2}$ University of Applied Sciences, Department of \\ Applied Sciences, Rheinbach, Germany \\ ${ }^{3}$ University Hospital, Department of Diabetes and \\ Metabolism, München-Schwabing, Germany \\ ${ }^{4}$ Institute for Clinical Research and Development, \\ IKFE, Rotenburg, Germany \\ ${ }^{5}$ University Hospital, Department of Endocrinology \\ and Metabolism, Dresden, Germany \\ ${ }^{6}$ Takeda Pharma GmbH, Aachen, Germany
}

\begin{abstract}
Background: Type 2 diabetes mellitus is associated with increased cardiovascular risk. One laboratory marker for cardiovascular risk assessment is highsensitivity C-reactive protein (hsCRP).

Methods: This cross-sectional study attempted to analyze the association of hsCRP levels with insulin resistance, $\beta$-cell dysfunction and macrovascular disease in 4270 non-insulin-treated patients with type 2 diabetes [2146 male, 2124 female; mean age $\pm S D$, $63.9 \pm 11.1$ years; body mass index (BMI) $30.1 \pm 5.5$ $\mathrm{kg} / \mathrm{m}^{2}$; disease duration $5.4 \pm 5.6$ years; hemoglobin $\mathrm{A}_{1 \mathrm{c}}\left(\mathrm{HbA}_{1 \mathrm{c}}\right) 6.8 \pm 1.3 \%$ ]. It consisted of a single morning visit with collection of a fasting blood sample. Observational parameters included several clinical scores and laboratory biomarkers.

Results: Stratification into cardiovascular risk groups according to hsCRP levels revealed that 934 patients had low risk (hsCRP $<1 \mathrm{mg} / \mathrm{L}$ ), 1369 patients had intermediate risk (hsCRP 1-3 mg/L), 1352 patients had high risk (hsCRP $>3-10 \mathrm{mg} / \mathrm{L}$ ), and 610 patients had unspecific hsCRP elevation ( $>10 \mathrm{mg} / \mathrm{L}$ ). Increased hsCRP levels were associated with other indicators of diabetes-related cardiovascular risk (homeostatic model assessment, intact proinsulin, insulin, BMI, $\beta$ cell dysfunction, all $p<0.001$ ), but showed no correlation with disease duration or glucose control. The majority of the patients were treated with diet $34.1 \%$; hsCRP levels $2.85 \pm 2.39 \mathrm{mg} / \mathrm{L}$ ) or metformin mono-

*Corresponding author: Prof. Dr. Andreas Pfützner, Institute for Clinical Research and Development, IKFE GmbH, Parcusstr. 8, 55116 Mainz, Germany

Phone: +49-6131-5763610, Fax: +49-6131-5763611, E-mail: andreasp@ikfe.de
\end{abstract}

therapy (21.1\%; $2.95 \pm 2.50 \mathrm{mg} / \mathrm{L}$ hsCRP). The highest hsCRP levels were observed in patients treated with sulfonylurea $(17.0 \% ; 3.00 \pm 2.43 \mathrm{mg} / \mathrm{L})$.

Conclusions: Our results indicate that hsCRP may be used as a cardiovascular risk marker in patients with type 2 diabetes mellitus and should be evaluated in further prospective studies.

Keywords: high-sensitivity C-reactive protein (hsCRP); homeostatic model assessment (HOMA); insulin resistance; intact proinsulin; type 2 diabetes.

\section{Introduction}

Patients with type 2 diabetes suffer from high cardiovascular morbidity and mortality based on extensive and accelerated arteriosclerosis (1). Coronary arteriosclerosis is increasingly recognized as a major complication and the leading cause of death in subjects with diabetes (2). It has been shown by laboratory and experimental studies that arteriosclerosis, as well as being a disease of lipid accumulation, represents a chronic inflammatory process (3). Thus, inflammatory markers have been investigated to identify potential adjunctive predictors for global assessment of cardiovascular risk (4-6). Several large-scale prospective epidemiological studies have demonstrated that highsensitivity $\mathrm{C}$-reactive protein (hsCRP) is a strong independent predictor for risk of future myocardial infarction and other consequences of arteriosclerosis, even in patients without known macrovascular disease $(7-10)$. With the recognition that inflammation is a critical component in the determination of plaque stability, CRP levels in the low-normal range were found to have predictive value for patients with acute coronary ischemia $(11,12)$. Levels of hsCRP $<1 \mathrm{mg} / \mathrm{L}$, 1-3 $\mathrm{mg} / \mathrm{L}$ and $>3 \mathrm{mg} / \mathrm{L}$ have been suggested to define low-, moderate-, and high-risk groups, while levels $>10 \mathrm{mg} / \mathrm{L}$ may indicate unspecific elevation consequent to a general inflammatory process (9).

In this analysis of the IRIS-II study population (13-15), we investigated the prevalence of hsCRP in a large population of 4270 orally treated type 2 diabetes mellitus patients, and its correlation with the prevalence of insulin resistance, $\beta$-cell dysfunction and cardiovascular events.

\section{Patients and methods}

The epidemiological cross-sectional study was performed in German patients with orally treated type 2 diabetes mellitus 
in accordance with Good Clinical Practice and the Declaration of Helsinki. The participants completed a standardized questionnaire, and blood samples were drawn in the fasting state. Actual therapy and the prevalence of microvascular (retinopathy, nephropathy, neuropathy) and macrovascular (stroke, coronary and peripheral artery disease, myocardial infarction) disease was assessed by an examination and collection of a detailed medical history. All laboratory data were measured in a central laboratory. Hemoglobin $A_{1 c}\left(H_{b A_{1 c}}\right)$ was measured by HPLC (Menarini, Neuss, Germany; reference range $4.4-6.0 \%)$. Glucose was determined using a glucose oxidase method (SuperGL; Ruhrtal Labortechnik, Delecke-Möhnesee, Germany). Insulin and intact proinsulin were determined by means of specific immunoassays (Sciema, Mainz, Germany) as previously published (16). HsCRP was assessed by means of a turbidimetric method (Olympus, Hamburg, Germany).

Assessment of insulin resistance was performed by analysis of fasting intact proinsulin values or homeostatic model assessment $\left(\mathrm{HOMA}_{\mathrm{IR}}\right)$ score calculation. Patients with intact proinsulin values exceeding the normal reference value of $11 \mathrm{pmol} / \mathrm{L}$ were considered to be insulin-resistant $(14,15)$. In the case of normal intact proinsulin values, $\mathrm{HOMA}_{\mathrm{IR}}$ score calculation was applied, as previously published (17). The estimate of insulin resistance by $\mathrm{HOMA}_{\mathrm{IR}}$ score was calculated using the following formula: fasting serum insulin $(\mu \mathrm{U} / \mathrm{mL}) \times$ fasting plasma glucose $(\mathrm{mmol} / \mathrm{L}) / 22.5$. As described by Hedblad et al. in a non-diabetic population, patients with $\mathrm{HOMA}_{\mathrm{IR}}$ score values exceeding the 75th percentile (i.e., 2.0) were considered to have insulin resistance (18). The $\beta$-cell dysfunction stage was assessed by considering steady state of insulin and intact proinsulin on the fasting morning, as previously reported (19).

\section{Statistical analysis}

As hsCRP has been reported to be associated with body mass index (BMI), hsCRP concentrations were adjusted for BMI before further analysis (20). To compare the means of the variables measured, Student's t-test, and the Mann-Whitney U-test were used. All tests were carried out as two-sided. Results with $\mathrm{p}$-values less than 0.05 were considered statis- tically significant. All calculations were made with the SPSS statistical package (version 9.0; SPSS Inc., Chicago, IL, USA).

\section{Results}

The study was completed by 2146 male and 2124 female patients with type 2 diabetes on oral medication and/or diet [age (mean \pm SD) $63.9 \pm 11.1$ years (range 21-96); disease duration $5.4 \pm 5.6$ years (range 0-52); BMI $30.1 \pm 5.5 \mathrm{~kg} / \mathrm{m}^{2}$ (range 16.0-67.2); waist/ hip ratio $1.0 \pm 0.1$ (range $0.6-1.4$ ); $\mathrm{HbA}_{1 \mathrm{c}} 6.8 \pm 1.3 \%$ (range $4.2-16.0 \%$ )]. No significant differences in demographic data could be observed between male and female patients.

Stratification of the patients into the different $\beta$-cell dysfunction stages, as previously defined (19), led to the following results: stage I (no insulin resistance or $\beta$-cell secretion disorder), 1042 patients (24.4\%); stage II (insulin resistance without secretion disorder), 1658 patients (38.8\%); and stage III (insulin resistance and secretion disorder), 1570 patients (36.7\%). The clinical characteristics of these groups are given in Table 1. Calculation of the mean hsCRP concentration in all three $\beta$-cell dysfunction groups revealed high risk levels for all stages of $\beta$-cell dysfunction. A higher cardiovascular risk was associated with more advanced stages of $\beta$-cell dysfunction $(p<0.001)$, as shown in Figure 1.

Stratification of the patients into the hsCRP risk groups as suggested by Ridker and Cook (9) revealed that 934 patients had low risk (hsCRP $<1 \mathrm{mg} / \mathrm{L}$, $21.8 \%), 1369$ patients were in the medium-risk group (hsCRP 1-3 mg/L, 32.0\%), and 1352 patients were in the high-risk group (hsCRP $>3-10 \mathrm{mg} / \mathrm{L}, 31.6 \%$ ). The number of patients with unspecific elevated hsCRP values (>10 $\mathrm{mg} / \mathrm{L}$ ) was $610(14.3 \%)$.

The differences observed for both hsCRP-associated cardiovascular risk and severity of $\beta$-cell dysfunc-

Table 1 Clinical and laboratory results for patients in the different $\beta$-cell dysfunction stages.

\begin{tabular}{|c|c|c|c|}
\hline \multirow[t]{2}{*}{ Parameter } & \multicolumn{3}{|c|}{$\beta$-Cell dysfunction stage } \\
\hline & I & II & III \\
\hline $\mathrm{n}$ & 1042 & 1658 & 1570 \\
\hline Gender, female/male & $501 / 538$ & $746 / 912$ & $899 / 672$ \\
\hline Age, years & $65 \pm 12$ & $64 \pm 11 * *$ & $65 \pm 11 *$ \\
\hline Disease duration, years & $5.5 \pm 6.1$ & $5.1 \pm 5.5$ & $5.4 \pm 5.2$ \\
\hline $\mathrm{BMI}, \mathrm{kg} / \mathrm{m}^{2}$ & $27.2 \pm 4.4$ & $30.5 \pm 5.2^{* * *}$ & $30.9 \pm 5.3^{* * *}$ \\
\hline Macrovascular disease, \% & 25.0 & 23.5 & 31.1 \\
\hline Hypertension, \% & 12.1 & 14.8 & 17.3 \\
\hline Neuropathy, \% & 12.2 & 14.8 & 17.3 \\
\hline Retinopathy, \% & 5.6 & 5.7 & 7.1 \\
\hline Nephropathy, \% & 16.0 & 14.9 & 21.2 \\
\hline HOMA score, $\mathrm{mU} \cdot \mathrm{mmol} / \mathrm{L}^{2}$ & $1.38 \pm 0.39$ & $3.66 \pm 2.22 * * *$ & $6.61 \pm 5.36 * * *$ \\
\hline $\mathrm{HbA}_{1 \mathrm{c}}, \%$ & $6.3 \pm 0.9$ & $6.7 \pm 1.2^{* * *}$ & $7.1 \pm 1.3^{* * *}$ \\
\hline hsCRP (not BMI-adjusted), mg/L & $4.0 \pm 7.4$ & $5.5 \pm 12.3^{* * *}$ & $6.8 \pm 14.0 * * *$ \\
\hline Insulin, $\mu \mathrm{U} / \mathrm{mL}$ & $6.1 \pm 2.0$ & $13.5 \pm 7.1^{* * *}$ & $20.4 \pm 13.3^{* * *}$ \\
\hline Glucose, mmol/L & $5.3 \pm 1.2$ & $6.6 \pm 1.7^{* * *}$ & $7.0 \pm 1.7 * * *$ \\
\hline Intact proinsulin, pmol/L & $4.3 \pm 2.0$ & $6.1 \pm 2.1 * * *$ & $22.1 \pm 15.8 * * *$ \\
\hline Triglyerides, $\mathrm{mmol} / \mathrm{L}$ & $1.45 \pm 1.65$ & $1.88 \pm 1.48^{* * *}$ & $2.31 \pm 1.74 * * *$ \\
\hline HDL, mmol/L & $1.3 \pm 0.35$ & $1.20 \pm 0.33^{* * *}$ & $1.08 \pm 0.28 * * *$ \\
\hline $\mathrm{LDL}, \mathrm{mmol} / \mathrm{L}$ & $3.13 \pm 0.83$ & $3.23 \pm 0.83$ & $3.18 \pm 0.8$ \\
\hline
\end{tabular}

${ }^{*} \mathrm{p}<0.05 ;{ }^{*} \mathrm{p}<0.01 ;{ }^{*}{ }^{*} \mathrm{p}<0.001$ vs. stage I. HDL, high-density lipoprotein; LDL, low-density lipoprotein. 


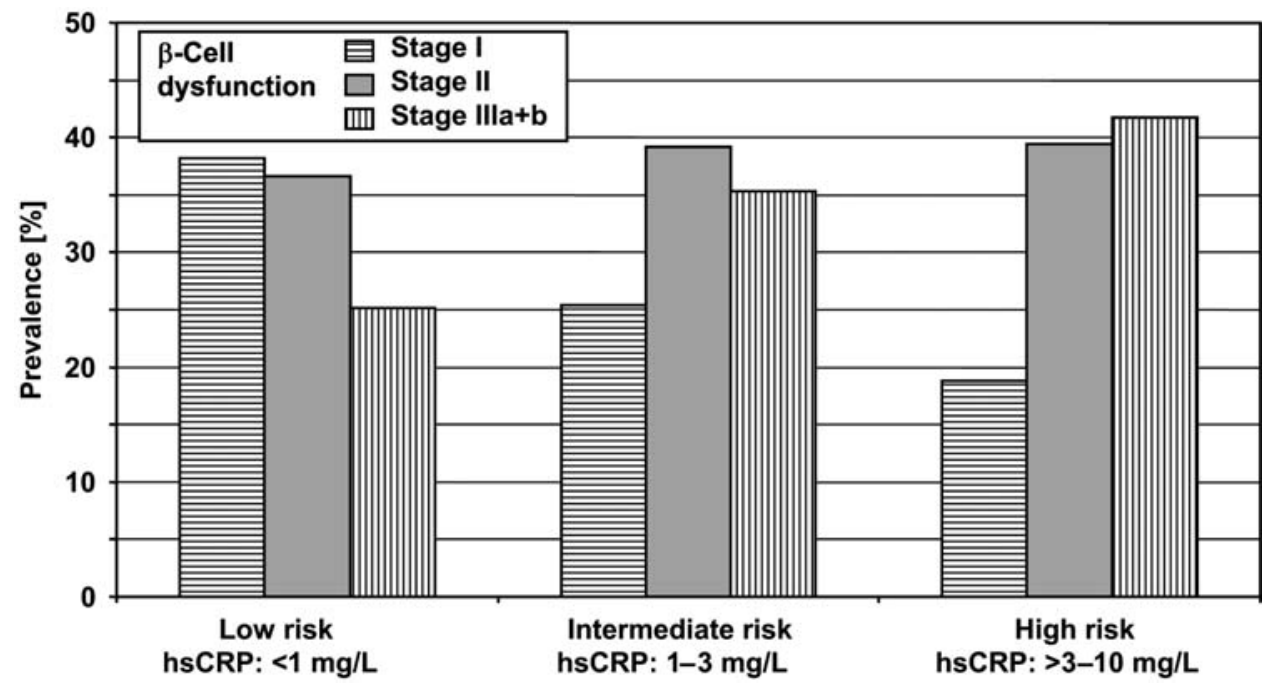

Figure 1 Stratification of patients (\% distribution) with high and low cardiovascular risk (according to hsCRP risk group definition) into the $\beta$-cell dysfunction stages as defined by Pfützner et al. (19). Higher cardiovascular risk is associated with a higher degree of $\beta$-cell dysfunction.

tion were independent of disease duration. A summary of the mean values for $\mathrm{HbA}_{1 \mathrm{c}}, \mathrm{HOMA}_{\mathrm{IR}}$, hsCRP, intact proinsulin, $\mathrm{BMI}$, disease duration, and the prevalence of macrovascular disease in the hsCRP risk groups is given in Table 2. It is evident that other wellknown cardiovascular risk indicators in type 2 diabetes mellitus, such as BMI, insulin resistance and intact proinsulin, are strongly correlated with the hsCRP risk staging according to Ridker and $\operatorname{Cook}(7,9)$, while the correlation with markers of glucose metabolism $\left(\mathrm{HbA}_{1 \mathrm{c}}\right.$, glucose) is less pronounced, although still significant because of the high number of patients.

The association of hsCRP values with prescribed therapy is shown in Figure 2. Patients receiving combination therapy of peroxisome proliferator activated receptor $\gamma$ (PPAR $\gamma$ ) agonists with metformin presented the lowest hsCRP mean values $(p<0.05)$.

\section{Discussion}

The cross-sectional IRIS study was initially performed to identify diagnostic parameters for insulin resistance in non-insulin-treated patients with type 2 dia- betes that are suitable for daily practice (13-15). Analysis of the same patient population presented here was performed to evaluate the correlation between cardiovascular risk, as identified by hsCRP risk assessment and $\beta$-cell dysfunction, and insulin resistance. In our non-insulin-treated type 2 diabetes patients with approximately 5 years of disease duration, the prevalence of macrovascular complications was $20-30 \%$. Serum levels of hsCRP were correlated with the severity of insulin resistance and $\beta$-cell dysfunction. All analysis groups, however, had hsCRP levels indicating high cardiovascular risk.

Chronic vascular inflammation may be the reason why hsCRP was elevated in our type 2 diabetes population. Strong correlations were evident between cardiovascular risk as assessed by hsCRP stratification and other parameters that are associated with increased risk or increased prevalence of cardiovascular complications in patients with type 2 diabetes, such as BMI, insulin resistance and elevated proinsulin (21-23). No or only weak associations, however, were evident for age, disease duration and the metabolic markers $\mathrm{HbA}_{1 \mathrm{c}}$ and fasting glucose. This result is in line with previous reports demonstrating that

Table 2 Clinical and laboratory results in the hsCRP risk groups.

\begin{tabular}{|c|c|c|c|c|}
\hline Parameter & $\begin{array}{l}\text { Low risk } \\
\text { (hsCRP < }<\mathrm{mg} / \mathrm{L})\end{array}$ & $\begin{array}{l}\text { Intermediate risk } \\
\text { (hsCRP 1-3 mg/L) }\end{array}$ & $\begin{array}{l}\text { High risk } \\
\text { (hsCRP > 3-10 mg/L) }\end{array}$ & $\begin{array}{l}\mathrm{p} \text {-Value for } \\
\text { correlation }\end{array}$ \\
\hline $\mathrm{n}$ & 934 & 1369 & 1352 & \\
\hline Age, years & $64 \pm 11$ & $65 \pm 11$ & $64 \pm 11$ & n.s. \\
\hline Disease duration, years & $6.3 \pm 6.5$ & $5.4 \pm 5.3$ & $5.1 \pm 5.3$ & n.s. \\
\hline $\mathrm{BMI}, \mathrm{kg} / \mathrm{m}^{2}$ & $27.3 \pm 4.1$ & $29.2 \pm 4.2$ & $31.2 \pm 5.3$ & $<0.001$ \\
\hline $\mathrm{HbA}_{1 \mathrm{c}}, \%$ & $6.59 \pm 1.10$ & $6.73 \pm 1.16$ & $6.95 \pm 1.32$ & n.s. \\
\hline Fasting glucose, $\mathrm{mmol} / \mathrm{L}$ & $5.9 \pm 1.6$ & $6.2 \pm 1.8$ & $6.4 \pm 1.9$ & $<0.05$ \\
\hline Fasting insulin, $\mu U / m L$ & $10.9 \pm 9.0$ & $13.2 \pm 9.6$ & $15.3 \pm 11.5$ & $<0.001$ \\
\hline $\mathrm{HOMA}_{\mathrm{IR}}$ score, $\mathrm{mU} \cdot \mathrm{mmol} / \mathrm{L}^{2}$ & $3.0 \pm 3.3$ & $3.7 \pm 3.3$ & $4.5 \pm 4.2$ & $<0.001$ \\
\hline Fasting intact proinsulin, pmol/L & $8.7 \pm 8.2$ & $13.2 \pm 9.6$ & $15.3 \pm 11.5$ & $<0.001$ \\
\hline hsCRP (BMI-adjusted), mg/L & $0.53 \pm 0.28$ & $1.87 \pm 0.57$ & $5.50 \pm 1.86$ & $<0.001$ \\
\hline Prevalence of macrovascular complication & $208(22.3 \%)$ & $382(27.9 \%)$ & $383(28.3 \%)$ & $<0.001$ \\
\hline Prevalence of microvascular complications & $260(27.8 \%)$ & $397(29.0 \%)$ & $406(30.0 \%)$ & $<0.001$ \\
\hline
\end{tabular}




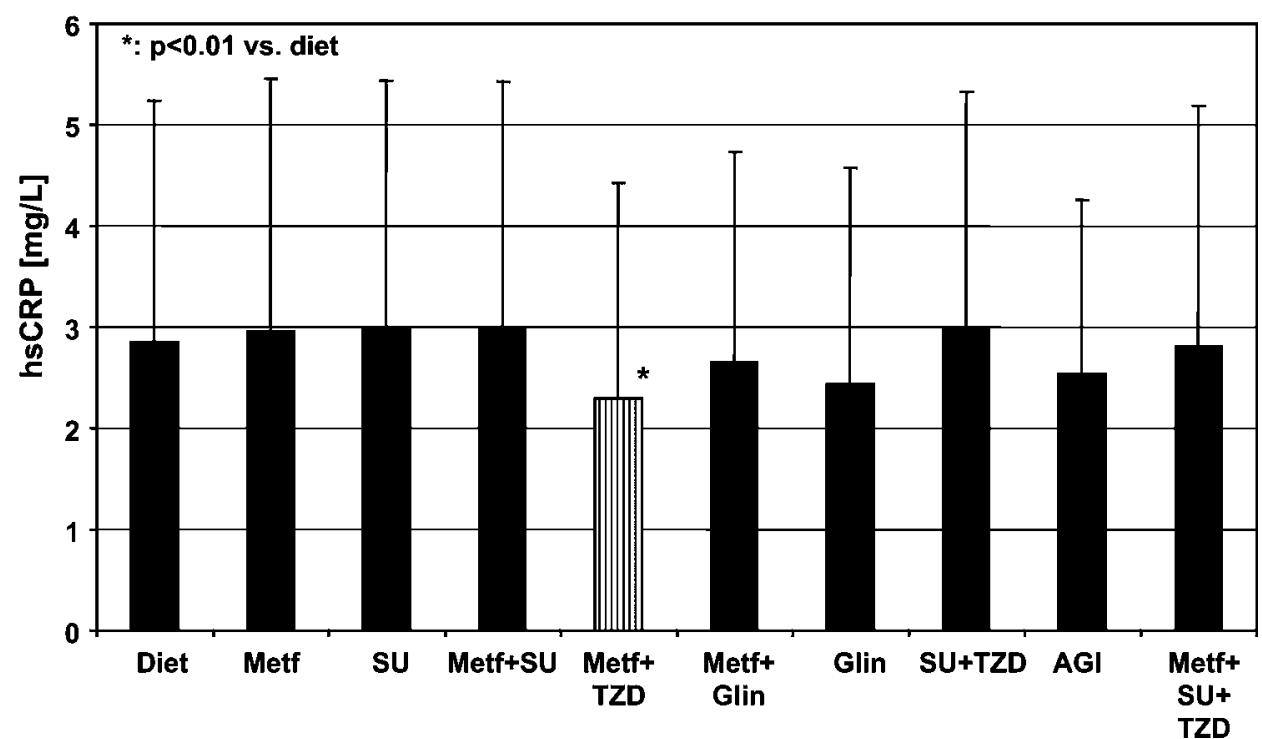

Figure 2 hsCRP values (adjusted for BMI) in patients treated with different oral treatment regimens; SU, sulfonylurea; Metf, metformin; TZD, thiazolidinediones; Glin, glinides; AGI, $\alpha$-glucosidase inhibitors.

postprandial glucose, rather than fasting glucose and $\mathrm{HbA}_{1 \mathrm{c}}$, is a strong predictor for cardiovascular mortality in patients with type 2 diabetes, as it may increase adhesion molecule secretion by endothelial cells when glucose concentrations increase above toxic levels (24).

A weakness of our study is the cross-sectional approach, which does not allow conclusions to be drawn about the impact of different therapeutic interventions on the metabolic and macrovascular risk scenario. It has, however, been demonstrated that impairment of $\beta$-cell dysfunction, as indicated by increased intact proinsulin levels, is associated with the use of insulinotropic substances, such as sulfonylurea drugs (15). In this analysis the highest hsCRP levels were also observed in patients receiving sulfonylurea therapy. These results support the hypothesis that cardiovascular disease risk may be associated with sulfonylurea treatment, as suspected decades ago $(25,26)$ and reported again recently $(27)$. Unfortunately, contradicting reports from studies such as the UK Prospective Diabetes Study (UKPDS) did not involve well enough characterized patient populations to allow direct comparison of the results (28). However, prospective studies using the same diagnostic markers as used in our current analysis have provided evidence of a beneficial impact of other therapeutic interventions compared to sulfonylurea therapy. Treatment of insulin resistance, e.g., using PPAR $y$ agonists seems to be an effective measure for decreasing cardiovascular and metabolic risk (29-32).

The importance of determining hsCRP in at-risk populations, such as diabetic patients, is further strengthened by recent reports suggesting that hsCRP is not only a risk indicator, but may also allow monitoring of arteriosclerosis regression during successful therapeutic interventions. Patients who have low CRP levels after statin therapy have better clinical outcomes than those with higher CRP levels, regardless of the resultant level of LDL cholesterol (33). In the
"Reversal of Atherosclerosis with Aggressive Lipid Lowering" study (REVERSAL), the reduced rate of progression of atherosclerosis associated with intensive statin treatment, as compared with moderate statin treatment, was significantly related to greater reductions in the levels of both atherogenic lipoproteins and CRP in patients with coronary artery disease (34). The same may hold true for patients with type 2 diabetes. Whether determination of hsCRP can provide additional risk information in type 2 diabetes, similar to the analysis of Ridker et al. in the Framingham Risk Score population (35), needs to be explored in prospective epidemiological trials.

The results of our analysis indicate that impaired insulin resistance and impaired $\beta$-cell function were associated with higher hsCRP levels and a higher prevalence of macrovascular complications. The clear association between hsCRP and other established or suspect risk markers support the suitability of hsCRP as a cardiovascular risk marker suitable for routine clinical use in type 2 diabetes mellitus.

\section{Acknowledgements}

We thank Mirjam Löbig and the IKFE laboratory team for professional performance of the laboratory measurements. The IRIS-II study was supported by an unrestricted grant from Takeda Pharma, Aachen, Germany.

\section{References}

1. Howard B, Rodriguez B, Bennet $P$, Harris $M$, Hamman $R$, Kuller $L$, et al. Prevention Conference VI: diabetes and cardiovascular disease: writing group I: epidemiology. Circulation 2002;105:e132-7.

2. Haffner SM, Lehto S, Ronnemaa T, Pyorala K, Laakso M. Mortality from coronary heart disease in subjects with type 2 diabetes and in nondiabetic subjects with and with- 
out prior myocardial infarction. N Engl J Med 1998; 339:229-34.

3. Ross R. Artherosclerosis: an inflammatory disease. N Engl J Med 1999;340:115-26.

4. Ridker PM. Evaluating novel cardiovascular risk factors: can we better predict heart attacks? Ann Intern Med 1999;130:933-7.

5. Ridker PM, Hennekens $\mathrm{CH}$, Buring JE, Rifai N. C-Reactive protein and other markers of inflammation in the prediction of cardiovascular disease in women. $\mathrm{N} \mathrm{Engl} \mathrm{J}$ Med 2000;342:836-43.

6. Willerson JT, Ridker PM. Inflammation as cardiovascular risk factor. Circulation 2004;109(Suppl 1):II2-10.

7. Ridker PM. High-sensitive C-reactive protein - potential adjunct for global risk assessment in the primary prevention of cardiovascular disease. Circulation 2001;103: 1813-8.

8. Koenig W, Sund M, Froelich M, Fischer HG, Lowel H, Doring $A$, et al. C-Reactive protein, a sensitive marker of inflammation, predicts future risk of coronary heart disease in initially healthy middle-aged men: results from the MONICA (Monitoring Trends and Determinants in Cardiovascular Disease) Augsburg Cohort Study, 1984 to 1992. Circulation 1999;99:237-42.

9. Ridker PM, Cook N. Clinical usefulness of very high and very low levels of $\mathrm{C}$-reactive protein across the full range of Framingham risk scores. Circulation 2004;109:1955-9.

10. Sellmayer A, Limmert T, Hoffmann U. High sensitivity Creactive protein in cardiovascular risk assessment. CRP mania or useful screening? Int Angiol 2003;22:15-23.

11. Morrow D, Rifai N, Antman E, Weiner DL, McCabe $\mathrm{CH}$, Cannon $\mathrm{CP}$, et al. C-Reactive protein is a potent predictor of mortality independently of and in combination with troponin $\mathrm{T}$ in acute coronary syndromes: a TIMI 11A substudy. Thrombolysis in Myocardial Infarction. J Am Coll Cardiol 1998;31:1460-5.

12. Maseri A. Inflammation, atherosclerosis and ischemic events: exploring the hidden side of the moon. N Engl J Med 1997;336:1014-6.

13. Forst T, Standl E, Hohberg C, Konrad T, Schulze J, Strotmann HJ, et al. IRIS-II Study: the IRIS-II score - assessment of a new clinical algorithm for the classification of insulin resistance in patients with type 2 diabetes. Diabet Med 2004;21:1149-53.

14. Pfützner A, Kunt T, Mondok A, Pahler S, Konrad T, Luebben $G$, et al. Fasting intact proinsulin is a highly specific predictor of insulin resistance in type 2 diabetes. Diabetes Care 2004;27:682-7.

15. Pfützner A, Standl E, Hohberg C, Konrad T, Strotmann HJ, Lübben G, et al. IRIS II Study: intact proinsulin is confirmed as highly specific marker for insulin resistance in a cross-sectional study design. Diabet Technol Ther 2005;7:478-86.

16. Pfützner A, Kunt T, Löbig M, Knesovic M, Forst T. Clinical and laboratory evaluation characteristics of two new chemiluminescence assays for intact and total proinsulin. Clin Chem Lab Med 2003;41:1234-8.

17. Matthews DR, Hosker JP, Rudenski AS, Naylor BA, Treacher DF, Turner RC. Homeostasis model assessment: insulin resistance and $\beta$-cell function from fasting plasma glucose and insulin concentrations in man. Diabetologia 1985;28:412-9.

18. Hedblad B, Nilsson P, Janzon L, Berglund G. Relation between insulin resistance and carotid intima-media thickness and stenosis in non-diabetic subjects. Results from a cross-sectional study in Malmo, Sweden. Diabetic Med 2000;17:299-307.

19. Pfützner $A$, Kann $P$, Pfützner $A H$, Kunt $T$, Larbig $M$, Weber MM, et al. Intact and total proinsulin: new aspects for diagnosis and treatment of type 2 diabetes. Clin Lab 2004;50:567-73.
20. Saito M, Ishimitsu T, Minami J, Ono H, Ohrui M, Matsuoka H. Relations of plasma high-sensitivity C-reactive protein to traditional cardiovascular risk factors. Atherosclerosis 2003;167:73-9.

21. Serrano Rios M. Relationship between obesity and the increased risk of major complications in non-insulindependent diabetes mellitus. Eur J Clin Invest 1998; 28(Suppl 2):14-7.

22. Haffner SM, Mykkänen L, Festa A, Burke JP, Stern MP. Insulin-resistant prediabetic subjects have more atherogenic risk factors than insulin-sensitive prediabetic subjects: implications for preventing coronary heart disease during the prediabetic state. Circulation 2000;101: 975-80.

23. Yudkin JS. Increased proinsulin concentrations and excess risk of coronary heart disease in patients with diabetes and prediabetes. Circulation 2002;106:e202.

24. Balkau B, Bertrais $S$, Ducimetiere $P$, Eschwege E. Is there a glycemic threshold for mortality risk? Diabetes Care 1999;22:696-9.

25. Huupponen R. Adverse cardiovascular effects of sulphonylurea drugs. Clinical significance. Med Toxicol 1987;2: 190-209.

26. Paice BJ, Paterson KR, Lawson DH. Undesired effects of the sulphonylurea drugs. Adverse Drug React Acute Poisoning Rev 1985;4:23-36.

27. Simpson SH, Majumdar SR, Tsuyuki RT, Eurich DT, Johnson JA. Dose-response relation between sulfonylurea drugs and mortality in type 2 diabetes mellitus: a population-based cohort study. Can Med Assoc J 2006; 174:169-74.

28. Riveline JP, Danchin N, Ledru F, Varroud-Vial M, Charpentier G. Sulfonylureas and cardiovascular effects: from experimental data to clinical use. Available data in humans and clinical applications. Diabetes Metab 2003;29:207-22.

29. Pfützner A, Marx N, Lübben G, Langenfeld M, Walcher D, Konrad T, et al. Improvement of cardiovascular risk markers by pioglitazone is independent from glycemic control - results from the Pioneer Study. J Am Coll Cardiol 2005;45:1925-31.

30. Langenfeld M, Forst T, Hohberg C, Kann P, Lübben G, Konrad $T$, et al. Pioglitazone decreases carotid intimamedia thickness independent of glycemic control in patients with type 2 diabetes mellitus. Circulation 2005;111:2525-31.

31. Pfützner A, Hohberg $C$, Lübben G, Pahler S, Pfützner $A H$ Kann $P$, et al. Pioneer Study: PPAR $\gamma$ activation results in an overall improvement of clinical and metabolic markers associated with insulin resistance independent from long-term glucose control. Horm Metab Res 2005;37: 510-5.

32. Pfützner A, Schöndorf T, Seidel D, Winkler K, Matthaei $S$, Hamann $A$, et al. Impact of rosiglitazone on $\beta$-cell function, insulin resistance and adiponektin concentrations - results from a double blind oral combination study with glimepiride. Metabolism 2006;55:20-5.

33. Ridker PM, Cannon CP, Morrow D, Rifai N, Rose LM, $\mathrm{McC}$ abe $\mathrm{CH}$, et al. C-Reactive protein levels and outcomes after statin therapy. N Engl J Med 2005;352:20-8.

34. Nissen SE, Tuzcu EM, Schoenhagen $P$, Crowe T, Sasiela WJ, Tsai J, et al. Statin therapy, LDL cholesterol, C-reactive protein, and coronary artery disease. N Engl J Med 2005;352:29-38.

35. Ridker PM, Wilson PWF, Grundy SM. Should C-reactive protein be added to metabolic syndrome and to assessment of cardiovascular risk? Circulation 2004;109: 2818-25.

Received November 12, 2005, accepted February 13, 2006 